\title{
ASSESSING THE PERFORMANCE OF LOGISTICS WITH THE SPECIAL REFERENCE TO SNP TRANSPORT LTD WITH SPECIFIC INDICATORS
}

\author{
*N. ARUNSANKAR \\ Associate Professor, Marian Institute of Management, Kuttikkanam, Idukki Dist, \\ Kerala, India-685531.arunsankar@miim.ac.in
}

\begin{abstract}
:
The logistics concept is today strictly related to commercial activities. In particular, transport and logistics activities are more and more responsible for the success of a company, because their performance strongly influence customer loyalty. An efficient and updated Logistics performance assessment system is essential for the financial health of a business. In this study aimed at measuring the Logistics Performance of SNP Transport Ltd by employing the specific tools are used to evaluate logistics performance. The study focuses on the analysis of the main indicators used to assess logistics performance of SNP Transport Ltd. The study can help to recognize the deficiencies of logistics sectors and find out the ways to progress performance.
\end{abstract}

Keywords: Logistics, SNP Ltd, Performance, Specific indictors, financial health

\subsection{INTRODUCTION ABOUT LOGISTICS INDUSTRY}

Logistics, as a business concept, evolved only in the 1950s. This was mainly due to the increasing complexity of supplying one's business with materials, and shipping out products in an increasingly globalized supply chain. The experts in this field are called Supply Chain Logisticians. Logistics is concerned with getting or transmitting the products and services where they are needed or when they are desired. It is difficult to accomplish any marketing or manufacturing operation without logistical support. Logistics involves in the integration of information, transportation, inventory, warehousing, material handling, and packaging. The operating responsibility of logistics is the geographical repositioning of raw materials, work in process, and finished inventories where required at the lowest cost possible. 


\subsection{STATEMENT OF THE PROBLEM}

The researcher has identified the problems being faced in the field of logistics the policies which are handled by the top management in SNP Transport Ltd the researcher has provided a frame work for an efficient functioning of logistics operations. The present research seeks to build a knowledge based frame work to topple down all the issues.

\subsection{OBJECTIVES OF THE STUDY}

1. To study logistics operations in general and in particular about SNP Transport Ltd.

2. To analyze the performance of SNP Transport Ltd.

\subsection{METHODOLOGY}

The validity of any research depends on the systematic method of collecting the data and analyzing the same in a sequential order. In the present study, an extensive use of both primary and secondary data is made.

\subsubsection{Sampling Design}

For collecting primary data, field survey technique was employed in the study area. First-hand information pertaining to the behavior, satisfaction, benefits accrued problems in mobilizing funds and optimum utilization of the funds from various sources under study were collected from five hundred sample respondents.

SNP Transport Ltd has thirty five offices at random in Kerala. The respondents were chosen from all thirty five offices at the rate of fifteen each. The selection of respondents was made in active consultation with finance managers, branch managers of various branch offices of SNP Transport Ltd and the research supervisor, so as to represent all categories such as rural, urban and metro. The respondents were selected on a simple random basis from the managers of SNP Transport Ltd

\subsubsection{Tools of Data Collection}

By virtue of a mass of data obtained from research survey, as well as data from secondary sources collected and presented in the present report, descriptive and analytical research was considered as most appropriate for the study. The research problems and the questionnaire were all framed accordingly. The suggestions offered in the final chapter of the present research report emerged from the inferences drawn from the study of the sample respondents' information who utilized funds for logistics operations. The researcher used closed -ended and open -ended questions in the questionnaire to collect primary data.

\subsection{HYPOTHESIS TESTING}

$>\mathrm{H}_{0}$ : there is no significant difference between expected delivery accuracy and performance of SNP Transport Ltd on delivery accuracy.

$>\mathrm{H}_{0}$ : there is no significant difference between expected material handling techniques and performance of SNP Transport Ltd on material handling.

$>\mathrm{H}_{0}$ : there is no significant difference between expected goods distribution method and performance of SNP Transport Ltd on distribution method.

$>\mathrm{H}_{0}$ : there is no significant difference between expected information system and information system of SNP Transport Ltd.

$>\mathrm{H}_{0}$ : there is no significant difference between expected packaging techniques and packaging techniques of SNP Transport Ltd.

$>\mathrm{H}_{0}$ : there is no significant difference expected customer friendliness and customer friendliness of SNP Transport Ltd.

$>\mathrm{H}_{0}$ : there is no significant difference between expected operating effectiveness and 
operating effectiveness of SNP Transport Ltd.

\subsection{RESULTS AND DISCUSSION}

\subsubsection{Performance of SNP Transport Ltd versus Delivery Accuracy}

Delivery Accuracy is the key factor which enables to measure the performance of SNP Transport Ltd and an attempt has been made to analyze the relationship between the delivery accuracy and the performance of SNP Transport Ltd. For this purpose the respondent's feedbacks have been classified based on the delivery accuracy viz., Order Processing Time, Delivery Consistency, Delivery frequency, Timely Delivery and Safety Delivery. With a view to find the degree of association between the delivery accuracy and the performance of SNP Transport Ltd, a two way table was prepared and is depicted in the following Table 1.1.

Table 1.1 Cross Table - Performance of SNP Transport Ltd versus Delivery Accuracy

\begin{tabular}{|c|c|c|c|c|c|c|c|c|}
\hline \multirow{2}{*}{$\begin{array}{l}\text { S. } \\
\text { No. }\end{array}$} & \multirow{2}{*}{$\begin{array}{l}\text { Delivery } \\
\text { Accuracy }\end{array}$} & \multicolumn{6}{|c|}{ Performance of SNP Transport Ltd } & \multirow[t]{2}{*}{ Total } \\
\hline & & Low & $\%$ & Medium & $\%$ & High & $\%$ & \\
\hline 1 & $\begin{array}{l}\text { Order } \\
\text { Processing } \\
\text { Time }\end{array}$ & 20 & 21.51 & 15 & 12 & 50 & 17.73 & 85 \\
\hline 2 & $\begin{array}{l}\text { Delivery } \\
\text { Accuracy }\end{array}$ & 20 & 21.51 & 20 & 16 & 60 & 21.28 & 100 \\
\hline 3 & $\begin{array}{l}\text { Delivery } \\
\text { Frequency }\end{array}$ & 15 & 16.13 & 30 & 24 & 68 & 24.11 & 113 \\
\hline 4 & $\begin{array}{l}\text { Timely } \\
\text { Delivery }\end{array}$ & 20 & 21.50 & 25 & 20 & 49 & 17.38 & 94 \\
\hline 5 & $\begin{array}{l}\text { Safety } \\
\text { Delivery }\end{array}$ & 18 & 19.35 & 35 & 28 & 55 & 19.5 & 108 \\
\hline & Total & 93 & 100 & 125 & 100 & 282 & 100 & 500 \\
\hline
\end{tabular}

The cross Table 4.1, displays the following respondents feel that frequency of delivery is necessary to measure the performance of SNP Transport Ltd. The order of preference extends to safety, consistency and timeliness. This is general as the people would not consider the order processing time, and also the logistics delivery. At a glance, one can observe the performance of SNP Transport Ltd is at high level and this may be based on the delivery characteristics. Verification of this is supported by the Chi-square test that is displayed in the subsequent Table 1.1.1 the underlined hypothesis taken for the Performance of SNP Transport Ltd versus Delivery Accuracy.

\section{Table 1.1.1 Chi-Square Statistics}

\begin{tabular}{|l|c|c|c|}
\hline & 2 value & Critical Value & Degrees of Freedom \\
\hline $\begin{array}{l}\text { Performance of } \\
\text { SNP Transport Ltd } \\
\text { and Delivery }\end{array}$ & 10.42 & 15.50 & 8 \\
Accuracy & & & \\
\hline
\end{tabular}

Analysis of Delivery accuracy and performance of SNP Transport Ltd shows that the underlined variables are independent of each other. Statistically, as the test statistic value is lesser than the critical value, the underlined hypothesis is accepted. This means that, Performance of SNP Transport Ltd is high as revealed by the cross table irrespective of various characteristics assumed. 


\subsubsection{Material handling and Performance of SNP Transport Ltd}

Performance of logistics could be measured by the way how logistics is handled during the course of delivery. Customers feel that their .products has to be handled gently with at most care. On the other hand this may not be possible as the logistics to be transported becomes larger and larger. This is where performance is justified. Gentle handling of material differs with respect to product nature, Volume of Material (Logistics), Speed of handle etc,. To ascertain the variation on these factors with performance, association measure of Chi-square test is employed. Cross Table 1.2, outlines the relationship in most general way.

Table 1.2 Cross Table - Performance of SNP Transport Ltd versus Material Handling

\begin{tabular}{|c|l|c|c|c|c|c|c|c|}
\hline $\begin{array}{c}\text { S. } \\
\text { No. }\end{array}$ & Material & \multicolumn{6}{|c|}{ Performance Of SNP Transport Ltd } & \multirow{2}{*}{ Total } \\
\cline { 3 - 8 } 1 & Handling & Low & \% & Medium & \% & High & \% & \\
\hline 2 & $\begin{array}{l}\text { Solumes to be } \\
\text { handled }\end{array}$ & 55 & 33.95 & 35 & 25.93 & 69 & 33.99 & 159 \\
\hline 3 & handling & 15 & 9.26 & 25 & 18.52 & 30 & 14.78 & 70 \\
\hline 4 & $\begin{array}{l}\text { Productivity } \\
\text { characteristics }\end{array}$ & 22 & 13.58 & 20 & 14.81 & 23 & 11.33 & 65 \\
\hline 5 & $\begin{array}{l}\text { Nature of the } \\
\text { Product }\end{array}$ & 40 & 24.69 & 30 & 22.22 & 55 & 27.09 & 125 \\
\hline & Total & 162 & 100 & 135 & 100 & 203 & 100 & 500 \\
\hline
\end{tabular}

The cross Table 1.2 highlights the preference of respondents towards material handling. Customers of logistics desire to have highest priority on Volume of products to be handled. This is most obvious which happens in general cases like purchases. The next character that follows the volume of material is the type of product to be transported. Generally, customers prefer to send their product with at most care with the type of product. This is mostly appropriate for the glass materials, electronic goods, perishable products etc,. To have connection with performance and the material handling general associative measure of categorical variables is applied. The result is shown in the Table 1.2.1 The Hypothesis undertaken is "Performance of SNP Transport Ltd is not related with Material Handling".

\section{Table 1.2.1 Chi-Square Statistics}

\begin{tabular}{|l|c|c|c|}
\hline & $\chi^{\mathbf{2}}$ value & Critical Value & $\begin{array}{c}\text { Degrees of } \\
\text { Freedom }\end{array}$ \\
\hline $\begin{array}{l}\text { Performance of SNP Transport } \\
\text { Ltd and Material Handling }\end{array}$ & 10.71 & 15.50 & 8 \\
\hline
\end{tabular}

The categorical associative measure has shown that the underlined variables are independent at each other. This is because of the result revealed by Chi-square test; likelihood value of test is more than the test statistic value. The researcher had the thought of "Performance of SNP Transport Ltd may be measured in the light of Material Handling". But the statistical procedure has disproved that, the performance is not based on material handling procedure, normally its performance is well.

\subsubsection{Distribution and the performance of SNP Transport Ltd}

Distribution shows that how the products are effectively distributed to the clients. Hence, an attempt is made to analyze the relationship between the distribution 
and the performance of SNP Transport Ltd. For the purpose of the study, the distribution was studied based on five classifications viz., Delivery Time, Lot Size, Packaging, Transportation mode, and Customer Service Norms. With a view to find the degree of association between the distribution and the performance of SNP Transport Ltd, a two way table was prepared and is depicted in the following Table 1.3 .

Table 1.3 Cross Table - Performance of SNP Transport Ltd versus Distribution

\begin{tabular}{|c|l|c|c|c|c|c|c|c|}
\hline \multirow{2}{*}{$\begin{array}{c}\text { S. } \\
\text { No. }\end{array}$} & \multirow{2}{*}{ Distribution } & \multicolumn{6}{|c|}{ Performance of SNP Transport Ltd } & \multirow{2}{*}{ Total } \\
\cline { 3 - 8 } & & Low & $\%$ & Medium & \% & High & \% & \\
\hline 1 & Delivery Time & 28 & 27.72 & 25 & 25.77 & 82 & 27.15 & 135 \\
\hline 2 & Lot Size & 25 & 24.75 & 20 & 20.62 & 45 & 14.9 & 90 \\
\hline 3 & Packaging & 15 & 14.85 & 25 & 25.77 & 55 & 18.21 & 95 \\
\hline 4 & $\begin{array}{l}\text { Transportation } \\
\text { mode }\end{array}$ & 20 & 19.8 & 15 & 15.46 & 70 & 23.18 & 105 \\
\hline 5 & $\begin{array}{l}\text { Customer } \\
\text { Service Norms }\end{array}$ & 13 & 12.87 & 12 & 12.37 & 50 & 16.56 & 75 \\
\hline \multicolumn{2}{|l|}{ Total } & 101 & 99.99 & 97 & 99.99 & 302 & 100 & 500 \\
\hline
\end{tabular}

The cross Table 1.3 highlights the preference of respondents towards distribution. Customers of logistics desire to have highest priority on Delivery Time. This is the most common fact that a customer will depends on timely delivery. To have connection with performance and the distribution, general associative measure of categorical variables is applied. The result is shown in the Table 1.3.1 The Hypothesis undertaken is "Performance of SNP Transport Ltd is not related with Distribution".

Table 1.3.1 Chi-Square Statistics

\begin{tabular}{|l|c|c|c|}
\hline & $\chi^{2}$ value & Critical Value & $\begin{array}{c}\text { Degrees of } \\
\text { Freedom }\end{array}$ \\
\hline $\begin{array}{l}\text { Performance of SNP } \\
\text { Transport Ltd and } \\
\text { Distribution }\end{array}$ & 11.38 & 15.70 & 8 \\
\hline
\end{tabular}

The categorical associative measure has shown that the underlined variables are independent of each other. This is because of the result revealed by Chisquare test; likelihood value of test is more than the test statistic value. The researcher had the thought of "Performance of SNP Transport Ltd may be measured in the light of Distribution". But the statistical procedure has disproved that, the performance is not based on distribution, normally its performance is well.

\subsubsection{Information System and the Performance of SNP Transport Ltd}

Information System helps to transfer the flow of information between the members in the SNP Transport Ltd in order to have an effective control over on its operation.

An attempt has been made to analyze the relationship between information system and performance of SNP Transport Ltd for this purpose the respondents have been classified based on information system viz., reliable, easy access, flexibility, interactive and timeliness. 
Table 1.4 Cross Table - Performance of SNP Transport Ltd versus Information system

\begin{tabular}{|c|c|c|c|c|c|c|c|c|}
\hline \multirow{2}{*}{$\begin{array}{l}\text { S. } \\
\text { No. }\end{array}$} & \multirow{2}{*}{$\begin{array}{l}\text { Information } \\
\text { System }\end{array}$} & \multicolumn{6}{|c|}{ Performance of SNP Transport Ltd } & \multirow{2}{*}{ Total } \\
\hline & & Low & $\%$ & Medium & $\%$ & High & $\%$ & \\
\hline 1 & Reliable & 20 & 22.22 & 30 & 20.69 & 50 & 18.87 & 100 \\
\hline 2 & Easy Access & 15 & 16.67 & 20 & 13.79 & 80 & 30.19 & 115 \\
\hline 3 & Flexibility & 28 & 31.11 & 35 & 24.14 & 35 & 13.21 & 98 \\
\hline 4 & Interactive & 15 & 16.67 & 25 & 17.24 & 55 & 20.75 & 95 \\
\hline 5 & Timeliness & 12 & 13.33 & 35 & 24.14 & 45 & 16.98 & 92 \\
\hline & Total & 90 & 100 & 145 & 100 & 265 & 100 & 500 \\
\hline
\end{tabular}

The cross Table 1.4 highlights the preference of respondents towards information system. In this, the customers of logistics desire to have highest priority on Easy access category. To have connection with performance and the information system, general associative measure of categorical variables is applied. The result is shown in the Table 1.4.1. The Hypothesis undertaken is "Performance of SNP Transport Ltd is related with information system".

Table 1.4.1 Chi-Square Statistics

\begin{tabular}{|l|c|c|c|}
\hline & $\chi^{\mathbf{2}}$ value & Critical Value & $\begin{array}{c}\text { Degree of } \\
\text { Freedom }\end{array}$ \\
\hline $\begin{array}{l}\text { Performance of SNP } \\
\begin{array}{l}\text { Transport Ltd Versus } \\
\text { information system }\end{array}\end{array}$ & 31.54 & 15.70 & 8 \\
\hline
\end{tabular}

The categorical associative measure has shown that the underlined variables are dependent on each other. This is because of the result revealed by Chi-square test; likelihood value of test is less than the test statistic value. The researcher had the thought of "Performance of SNP Transport Ltd may not be measured in the light of information".

\subsubsection{Packaging and the performance of SNP Transport Ltd}

Packaging plays an important role in transportation and distribution of logistics management. Customized packaging always ensures the safety of goods. An attempt is made to analyze the relationship between packaging and the performance of SNP Transport Ltd For this purpose, the respondents' feedback have been collected and classified into Physical Dimensions, Reusability, Waste disposal, Design and Handling.

Table 1.5 Cross Table - Performance of SNP Transport Ltd versus Packaging

\begin{tabular}{|l|l|c|c|c|c|c|c|c|}
\hline S. & \multirow{2}{*}{ Packaging } & \multicolumn{6}{|c|}{ Performance of SNP Transport Ltd } & \multirow{2}{*}{ Total } \\
\cline { 3 - 8 } & Low & \% & Medium & \% & High & \% & \\
\hline 1 & $\begin{array}{l}\text { Physical } \\
\text { Dimensions }\end{array}$ & 15 & 15 & 25 & 16.67 & 35 & 14 & $\mathbf{7 5}$ \\
\hline 2 & Reusability & 20 & 20 & 30 & 20 & 40 & 16 & $\mathbf{9 0}$ \\
\hline 3 & $\begin{array}{l}\text { Waste } \\
\text { disposal }\end{array}$ & 25 & 25 & 25 & 16.67 & 50 & 20 & $\mathbf{1 0 0}$ \\
\hline 4 & Design & 15 & 15 & 35 & 23.33 & 60 & 24 & $\mathbf{1 1 0}$ \\
\hline 5 & Handling & 25 & 25 & 35 & 23.33 & 65 & 26 & $\mathbf{1 2 5}$ \\
\hline \multicolumn{2}{|c|}{ Total } & $\mathbf{1 0 0}$ & $\mathbf{1 0 0}$ & $\mathbf{1 5 0}$ & $\mathbf{1 0 0}$ & $\mathbf{2 5 0}$ & $\mathbf{1 0 0}$ & $\mathbf{5 0 0}$ \\
\hline
\end{tabular}

The cross Table 1.5 exhibits that, most of the respondents feel handling packages is a necessary tool for measuring the performance of SNP Transport Ltd At a glance, one 
can observe that the performance of SNP Transport Ltd is at high level and this may be based on the handling of packages with care. Verification of this is supported by the Chi-square test that is displayed in the subsequent Table 1.5.1. The underlined hypothesis taken for the same is that "Performance of SNP Transport Ltd is independent of Packaging".

Table 1.5.1 Chi-Square Statistics

\begin{tabular}{|l|c|c|c|}
\hline & $\chi^{2}$ Value & Critical Value & $\begin{array}{c}\text { Degree of } \\
\text { Freedom }\end{array}$ \\
\hline $\begin{array}{l}\text { Performance of SNP } \\
\text { Transport Ltd and } \\
\text { Packaging }\end{array}$ & 6.71 & 15.70 & 8 \\
\hline
\end{tabular}

The categorical associative measure has shown that the underlined variables are independent of each other. This is because of the result revealed by Chi-square test; likelihood value of test is less than the test statistic value. The researcher had the thought of "Performance of SNP Transport Ltd may be measured in the light of Packaging".

\subsubsection{Customer Friendliness and Performance of SNP Transport Ltd}

Customer Friendliness is an important factor that has an effective control on its operation by way of providing flexible service to the customers. An attempt has been made to study the relationship between the Customer Friendliness and performance of SNP Transport Ltd For this purpose the respondents' feedback have been collected and classified according to information flow, dependency, timely work, communication and relationship. The below cross table exhibits that the Customer Friendliness and performance of SNP Transport Ltd.

Table 1.6 Cross Table - Performance of SNP Transport Ltd versus Customer Friendliness

\begin{tabular}{|c|l|c|c|c|c|c|c|c|}
\hline S. & Customer & \multicolumn{6}{|c|}{ Performance of SNP Transport Ltd } & \multirow{2}{*}{ Total } \\
\cline { 3 - 8 } No. & Friendliness & Low & $\mathbf{\%}$ & Medium & \% & High & \% & \\
\hline 1 & Information Flow & 20 & 23.53 & 30 & 20 & 45 & 16.98 & $\mathbf{9 5}$ \\
\hline 2 & Dependency & 10 & 11.76 & 35 & 23.33 & 40 & 15.09 & $\mathbf{8 5}$ \\
\hline 3 & Timely Work & 25 & 29.42 & 30 & 20 & 60 & 22.64 & $\mathbf{1 1 5}$ \\
\hline 4 & Communication & 20 & 23.53 & 20 & 13.34 & 55 & 20.75 & $\mathbf{9 5}$ \\
\hline 5 & Relationship & 10 & 11.76 & 35 & 23.33 & 65 & 24.54 & $\mathbf{1 1 0}$ \\
\hline
\end{tabular}

The cross Table 1.6 highlights that the maximum percentage of high level of satisfied respondents with the relationship extended by SNP Transport Ltd among respondents, who have availed the service of SNP Transport Ltd To have connection with performance and the customer friendliness, general associative measure of categorical variables is applied. The result is shown in the Table 1.6.1. The Hypothesis undertaken is "Performance of SNP Transport Ltd is related with customer friendliness". 
Table 1.6.1 Chi-Square Statistics

\begin{tabular}{|l|c|c|c|}
\hline & $\chi^{2}$ Value & Critical Value & $\begin{array}{c}\text { Degree of } \\
\text { Freedom }\end{array}$ \\
\hline $\begin{array}{l}\text { Performance of SNP } \\
\text { Transport Ltd and } \\
\text { Customer Friendliness }\end{array}$ & 18 & 15.70 & 8 \\
\hline
\end{tabular}

It is inferred from the above table that, there is a close relationship between the performance of SNP Transport Ltd and Customer friendliness perceived by the respondents.

\subsubsection{Operating Effectiveness and Performance of SNP Transport Ltd}

Operating Effectiveness is a key element for the logistics service providers in terms of ensuring the quality of operations to their customers. An effort has been made to study the relationship between the operating effectiveness and performance of SNP Transport Ltd. For this purpose the respondents' feedback have been collected and classified according to the quality of operations, flexibility, and speed of operation, capacity utilization and total productivity. The below cross table exhibits the operating effectiveness and performance of SNP Transport Ltd.

Table 1.7 Cross Table - Performance of SNP Transport Ltd versus Operating Effectiveness

\begin{tabular}{|c|c|c|c|c|c|c|c|c|}
\hline \multirow{2}{*}{$\begin{array}{l}\text { S. } \\
\text { No. }\end{array}$} & \multirow{2}{*}{$\begin{array}{c}\text { Operating } \\
\text { effectiveness }\end{array}$} & \multicolumn{6}{|c|}{ Performance of SNP Transport Ltd } & \multirow{2}{*}{ Total } \\
\hline & & Low & $\%$ & Medium & $\%$ & High & $\%$ & \\
\hline 1 & $\begin{array}{l}\text { Quality of } \\
\text { Operations }\end{array}$ & 40 & 28.17 & 28 & 20 & 45 & 20.64 & 113 \\
\hline 2 & Flexibility & 20 & 14.08 & 30 & 21.42 & 33 & 15.14 & 83 \\
\hline 3 & $\begin{array}{ll}\begin{array}{l}\text { Speed } \\
\text { operation }\end{array} & \text { of } \\
\end{array}$ & 35 & 24.65 & 35 & 25 & 55 & 25.23 & 125 \\
\hline 4 & $\begin{array}{l}\text { Capacity } \\
\text { utilization }\end{array}$ & 25 & 17.61 & 27 & 19.29 & 50 & 22.93 & 102 \\
\hline 5 & $\begin{array}{l}\text { Total } \\
\text { Productivity }\end{array}$ & 22 & 15.49 & 20 & 14.29 & 35 & 16.06 & 77 \\
\hline & Total & 142 & 100 & 140 & 100 & 218 & 100 & 500 \\
\hline
\end{tabular}

The cross table 1.7 given above displays, the response of customers across Performance of SNP Transport Ltd and the operational service given to the customers. It is noted that, customers who come for service expects the service to be completed in a fast manner. They may have some sort of characteristics in their mind regarding the service. But the major phenomenon that determines performance is fast service. Followed by the fast service the next factor is quality service. This is supported by the highest level of $25 \%$ of respondents. The next highest level of $22.5 \%$ of respondents prefers to have Quality service. To authenticate the above statement, Chi-square analysis is carried out.

Table 1.7.1 Chi-Square Statistics

\begin{tabular}{|l|c|c|c|}
\hline & $\chi^{\mathbf{2}}$ Value & Critical Value & $\begin{array}{c}\text { Degree of } \\
\text { Freedom }\end{array}$ \\
\hline $\begin{array}{l}\text { Performance of SNP } \\
\text { Transport Ltd and } \\
\text { Operating Effectiveness }\end{array}$ & 07.03 & 15.70 & 8 \\
\hline
\end{tabular}


It could be noted from Table 1.7.1 that the calculated chi-square value is lesser than the critical value. This leads to a conclusion that there is no relationship between performance of SNP Transport Ltd and Operating effectiveness. Whether the operating process is different or not, the customers get satisfied with the available service which is provided by SNP Transport Ltd.

\subsection{FINDINGS OF THE STUDY}

The following are the major findings arrived from the analysis: the employee's level of happiness and satisfaction which in turn reflects their services to the customers and their rapport, the analysis brings to light the following findings on financial performance.

$>$ The overall study reveals that SNP Transport Ltd is the market leader in the logistic industry. On the other hand,

$>$ It is identified from the analysis that a good majority of the respondents felt that the service provided by SNP Transport Ltd is satisfactory.

$>$ The performance of SNP Transport Ltd is the best in the way how materials are handled during the logistics by SNP Transport Ltd.

$>$ The information system used in SNP Transport Ltd has the impact on performance of SNP Transport Ltd.

$>$ The performance of the SNP Transport Ltd is measured based on the relationship it had when the customers approached SNP Transport Ltd for service.

$>$ The performance of SNP Transport Ltd is not measured based on the manner by which the customers get packed.

$>$ The performance of SNP Transport Ltd is satisfactory which is not based on effective operation which is followed in SNP Transport Ltd while delivering the service to the customer.

The researcher has identified that there are few factors which are highly influencing the top management while taking financial decisions in terms of utilization of the mobilized funds for its logistics operation.

\subsection{SUGGESTIONS OF THE STUDY}

$>$ A good customer relationship is more important to enhance the business performance, especially in service oriented organizations. The transport corporations of India have to establish a good customer management with the present and prospective customers.

$>$ On-line communication about new services offered by the SNP Transport Ltd can be given to the existing customers from time to time.

$>$ Conducting regular training programs for the staff of SNP Transport Ltd may help to deliver better quality of services to the customers and also for its survival.

$>$ SNP Transport Ltd has to inspire the customers by its service which will initiate the existing customer to introduce or recommend new customers.

$>$ SNP Transport Ltd needs to be competent in modern technology for its survival.

$>$ The good communication skills, logistics operations skills, understanding the new technology and the ability of logistics managers to plan and forecast for the logistics management are highly regarded as desired skills of future logistics managers.

$>$ Based on the research work, the integrated model has been developed for the better utilization of the mobilized funds for the logistics business.

$>$ The government should initiate and implement customized policy, uniform tax to the logistic service providers for the effective operation.

$>$ The reusable or disposable materials should be used with the packing of goods in order to save the environment.

$>$ The customer friendliness needs to be enhanced with their operation systems in order 
to improve the efficiency of SNP Transport Ltd while delivering the good to the customers.

\subsection{CONCLUSION}

The performance analysis shows that the Transport Corporation India ltd is the market leader and it has performed well than any other logistics service providers. On the other hand, most logistics service provider's offers almost similar services and the customers have little to choose by way of difference in the effective terms of a service. It is in such a situation that good marketing back-up, with service orientation, is bound to become very useful and attractive.

However, a lot has been changing with the government finally realizing the importance of infrastructure and demonstrating a strong commitment towards providing the same along with creating conducive regulations. Regulations around rationalization of tax structures, proposed introduction of GST and prevention of overloading are creating a favorable environment, in which the sector can flourish. Initiatives taken by the government and innovations by industry players are helping them in leveraging the economies of scale and to provide integrated logistics solutions which are cost effective. At the same time, emphasis should be given for the integration of IT enabled technology in the sector. With latest technology, logistics service providers will no longer be restricted to the geographical boundaries but can expand their business to any location.

\section{REFERENCES}

1 Bo Yuan and Chuanxu Wang, "Research on the Third Part Logistics Company's Financing Pricing under Conditions of Permissible Delay in Payments for Exponentially Deteriorating roducts", IEEE,pp. 861-864, 2010.

2 Bolin LIU and Shaochuan FU, "Efficiency Measurement of Logistics Public Companies Basing on the Modified DEA Model", IEEE, pp.601-605, 2009.

3 Carlos Sanchís-Pedregosa, José A. D. M achuca and María del Mar GonzálezZamora, "Logistics Outsourcing: Performance Models and Financial and Operational Indicators”, IEEE, pp-96-101, 2011.

4 Celik Parkan and Rameshwar Dubey, "Recent Developments in the practice of supply chain Management and Logistics in India Reports”, Portuguese Journal of Management Studies, Vol. XIV, No. 1, 2009.

5 Chen Lihong and Peng Fangchun, "Study on Small and Medium-sized Enterprise Supply Chain Financing”, IEEE, 2011.

6 Chen Shen, Li-rning Zhao and Yue, L. "The research on the constitution of Financial Logistics Management System”, IEEE, pp.1448-1452, 2010.

7 Chen, Xiang-Feng and Xie Xiaoyan, "The value of integrated logistics and finance services of third party logistics firms", International Journal of Services Operations and Informatics, Vol. 4, No. 4, pp. 333-351, 2009.

8 Ding and Xiang, "The Listed Company's Financial Evaluation Based on PCALogistic Regression Model”, IEEE, pp.168-171, 2010.

9 Duan and Weichang, "A Rapid Decision-Making Model in Supply Chain Finance Emergency Based on GDSS”, IEEE, pp-539-543, 2009.

10 Duan Weichang, "Benefits Distribution Model of High-risk Projects Based on Deferral Options for Supply Chain Finance”, IEEE, pp.84-87, 2010.

11 Haipeng Wang, "Study on Supply Chain Finance in E-business Circumstances", IEEE, pp-507-509, 2010.

12 He Juan, Chen Xiangfeng and Li Ming, "Analysis of Logistics Financing Risk Based 
on the Structural Equation Modeling”, IEEE, 2009.

13 Hu Qin, "Risk Analysis and Countermeasures Concerning of SMEs in China under Logistical Finance”, IEEE, pp. 326-329, 2011.

14 Indian Logistics Industry”, Scope Marketing \& Information Solutions, 2010.

15 Jian Xu and Xiqin Han, "Analysis on Linkage Mechanism between Manufacturing and Logistics Industry”, IEEE, pp. 3200-3203, 2010.

16 Jiancai Yang, "The Empirical Analysis of Automobile Logistics Based on The Principle Component Analysis", IEEE, 2011.

17 Li Wenjing and Xia Chunyu, "The Impact of Logistics Mode on Retailer's Logistics Performance Measurement System”, IEEE, 2010.

18 Li, Yixue' Wang, Shouyang' Feng, Gengzhong and Lai, Kin Keung' "Comparative analysis of risk control in logistics and supply chain finance under different pledge fashions", International Journal of Revenue Management, Vol.5, No. 2-3, pp. 121 144, 2011.

19 Lijuan and Xuyu, "Optimal-decision Research on Ordering Financing Based on Supply Chain Finance”, IEEE, 2010.

20 Liu Xiang, "A multiple criteria decision-making method for enterprise supply chain finance cooperative systems", IEEE, pp.120-125, 2009.

21 Liu Xiang, "Context-aware data mining methodology for supply chain finance cooperative systems", IEEE, pp.301-306, 2009.

22 Lu Zheng-hua, Dai Qi-li and Chen Xiu-de, "An Analysis on Logistics Finance Based on Third Party Logistics and the Financing Model", IEEE, 2009.

23 Lu Zheng-hua, Dai Qi-li and Chen Xiu-de, "An Analysis on Logistics Finance Based on Third Party Logistics and the Financing Model", 2009.

24 Lu Zheng-hua, Dai Qi-li and Chen Xiu-de, "An Analysis on Logistics Finance Based on Third Party Logistics and the Financing Model", IEEE, 2009.

25 Luo Jianfeng and Ma Tianshan, "An Comprehensive Rating Model of Manufacturing Enterprise's Credit Risk Based on Logistics Finance”, IEEE, V15-290-293, 2010.

26 Luo Jianfeng, Zhou Lingyun and Ma Tianshan, "A Comprehensive Evaluation Method of Logistics Company's Credit Risk Based on Logistics Finance”, IEEE , pp. 299-302, 2010.

27 Miao He, Changrui Ren, Qinhua Wang and Jin Dong, "An Innovative Stochastic Dynamic Model to Three-stage Supply Chain Finance”, IEEE, pp.13-318, 2011.

28 Miao He, Changrui Ren, Qinhua Wang and Jin Dong, "An Innovative Stochastic Dynamic Model to Three-stage Supply Chain Finance”, IEEE, pp.313-318, 2011. 